\title{
A Study on the BIM Application of Green Building Certification System
}

\author{
Hanjong Jun ${ }^{1}$, Iksung $\mathrm{Kim}^{2}$, Yongju Lee ${ }^{3}$ and Mikyoung Kim** \\ ${ }^{1}$ Professor, Department of Architecture, Architectural Design Computing Centre, Hanyang University, Korea \\ ${ }^{2}$ Researcher, Architectural Design Computing Centre, Hanyang University, Korea \\ ${ }^{3}$ Graduate Student, School of Architecture, Hanyang University, Korea \\ ${ }^{4}$ Ph.D. Candidate, School of Architecture, Hanyang University, Korea
}

\begin{abstract}
Driven by governments, all countries are enacting laws related to environmental improvements and establishing policies to reduce greenhouse gases (GHG). Because $26.9 \%$ of the reduction plans from a total of $30 \%$ of national GHG reduction targets is set in the building area, most countries are inducing green building expansion through the implementation of green building standards that reflect the countries' standards to achieve the 2020 target. To construct buildings that conform to the certification by satisfying the eco-friendliness of buildings, studies that consider this requirement should be performed from the initial design stage. However, there are several complicated work processes and problems in analysing items in detail, recognizing demand related to data, and applying data to work.

Accordingly, the development of new applicable techniques is required that can support the information of detailed items in certification more efficiently to vitalize green buildings based on green building standards. From this perspective, this study seeks to propose a practical method to support the design of green buildings using a GBT, BIM-based green template, and to develop the supportive and evaluative environment for the demands of green building standards via GBT.
\end{abstract}

Keywords: Green Standard for Energy and Environmental Design (G-SEED); Green Building; Green BIM Template (GBT); Building Information Modelling (BIM); Level of Detail (LOD)

\section{Introduction \\ 1.1 Research Background and Purpose}

Green buildings suggest the direction to follow to achieve the sustainable goal of the construction industry; for related information and standards, one can refer to green building certification programs. Most countries manage green building certification programs with applicable standards; typical examples are Leadership in Energy and Environmental Design (LEED) from the USA, Building Research Establishment Environmental Assessment Methodology (BREEAM) from the UK, Comprehensive Assessment System for Built Environment Efficiency (CASBEE) from Japan, and Green Standard for Energy and Environmental Design (G-SEED) from Korea.

*Contact Author: Mikyoung Kim, Ph.D. Candidate,

School of Architecture, Hanyang University

406-2 FTC, 17 Haengdang-dong Sungdong-Gu,

Seoul, Republic of Korea

Tel: +82-102-829-3523 Fax: +82-222-200-264

E-mail: nnyang2mk@hanyang.ac.kr

(Received April 8, 2014 ; accepted November 1, 2014)
With respect to the evaluation method for G-SEED implemented in Korea, inspectors perform evaluations manually based on design documents and related materials presented by the designers. However, because the detailed standards required for G-SEED certification are diverse and the evaluation process is complicated, the information to review and the work processes required to compute the certification grade are increasing. Therefore, receiving a G-SEED certification grade is time-consuming because of the amount of time required to conduct such an evaluation. Furthermore, problems such as missing data and subjective decisions might occur, thereby destroying credibility. In addition, as the amount of required design documents and related materials increase, unnecessary resources are wasted, causing environmental problems. Accordingly, to revitalize the construction of green buildings based on G-SEED, the development of a new technique that provides effective support with respect to detailed certification items is required.

This study seeks to propose a Green BIM Template (GBT), a Building Information Modelling (BIM)based green template, and to construct an evaluation system that users (designers) or reviewers can utilize to evaluate G-SEED certifications. GBT is a platform 
that provides the environment to automatically extract the information required to evaluate the G-SEED standard through the BIM model that contains environmental performance information and computes the final certification grade. According to the automatic certification process and evaluation, users can find objective information quickly and confirm a trusting certification grade. Moreover, a simplified process, compared to the existing green building certification programs, reduces cost and time, thus providing convenience to users. Accordingly, this program contributes to the revitalization of improved green buildings because a wider approach becomes available that considers the users' situation, and information analysis and management also become available.

\subsection{Study Method and Procedure}

This study seeks to revitalize green buildings through the establishment of BIM-based systems for objective and effective green building certification evaluation (G-SEED). The scope of the study is set based on the evaluation standards of G-SEED for apartment houses that were announced on June 2013; Autodesk Revit $^{\circledR}$, Microsoft Access and Microsoft Excel were used as the development platform. For users who have difficulty accessing green building designs, we performed this study with the methods described in the next paragraphs in order to find the techniques for developing the GBT prototype that is the evaluation environment through which users can access green buildings by a system that uses G-SEED, and to find the plan for its use.

First, the background, purpose, scope, and method of this study are introduced in the instruction part.

Second, the BIM-based green template concept is established by managing the need of BIM for green buildings via a theoretical study, and green building certification programs from Korea and overseas are analysed.

Third, the BIM application method is set via the analysis of detailed G-SEED items, and its applicability is examined.

Fourth, the GBT concept and structure are established, the process applied to G-SEED is organized, and the system for obtaining the final G-SEED certification grade is constructed.

Fifth, the method to utilize the constructed GBT is sought.

Lastly, the supplemental needs of the constructed BIM-based system and the establishment of the development plan in the future are managed.

\section{Theoretical Review}

\subsection{Concept of BIM Template for Green Building}

According to the dictionary definition, a template is a consistent input form that is arranged with a certain frequently used structure in order to obtain an outcome suitable for a specific purpose. Users can obtain the outcome they require by quickly and thoroughly inputting data in advance through the template (Yang, 2012). Accordingly, the template has the following functional characteristics:

- Classification according to the purpose of the template

- Reuse for repetitive work type

- Group input data defined in advance

- Process data via the designated input-output form

- Minimize users' action of missing the data to input, thus reducing mistakes

- Production of consistent and effective outcome

Accordingly, the template that actualizes the functions necessary to apply to BIM-based building design processes can be defined as a BIM template. If such a template is applied to real works, the BIM library and information type can be standardized, and all workers can be provided with a consistent working environment. Moreover, various alternative methods can be considered more quickly than when using $2 \mathrm{D}$ based design by utilizing BIM data types. The consistent and effective outcome obtained through the BIM template can be used in the construction area as well as the building design area (Lee et al., 2011).

\subsection{Green Standard for Energy and Environmental} Design (G-SEED)

In February 2013, green building-related laws, in which targets and certification standards overlapped, were consolidated when G-SEED, an integrated green building certification program, was officially launched. This is the program that grants green building certification to buildings that contribute to energy savings and reduce environmental pollution over entire processes, such as design, construction, maintenance, and management.

Table 1. G-SEED Characteristics

\begin{tabular}{|c|c|}
\hline Division & Content \\
\hline $\begin{array}{l}\text { Target buildings for } \\
\text { certification (eight } \\
\text { types of buildings) }\end{array}$ & $\begin{array}{l}\text { Apartment building, Complex } \\
\text { building, Business building, School } \\
\text { facility, Accommodation facility, } \\
\text { Small house, etc. }\end{array}$ \\
\hline $\begin{array}{l}\text { Certification } \\
\text { judgment area (eight } \\
\text { areas) }\end{array}$ & $\begin{array}{l}\text { Use of land and transportation, } \\
\text { Energy and environmental pollution, } \\
\text { Material and resources, Water } \\
\text { circulation management, Maintenance } \\
\text { and man agement, Ecological } \\
\text { environment, Indoor environment, } \\
\text { Building performance area. }\end{array}$ \\
\hline $\begin{array}{l}\text { Evaluation items } \\
\text { (Based on apartment } \\
\text { building) }\end{array}$ & Total 54 items \\
\hline Class & $\begin{array}{l}\text { Best (Green first class), Excellent } \\
\text { (Green second class), Good (Green } \\
\text { third class), Average (Green fourth } \\
\text { class). }\end{array}$ \\
\hline Incentive & $\begin{array}{l}\text { Reduction of acquisition tax and } \\
\text { registration tax, Alleviation of } \\
\text { building regulations such as ratio } \\
\text { of floor area to site, Reduction of } \\
\text { environmental improvement charges. }\end{array}$ \\
\hline
\end{tabular}




\section{BIM Application Method for G-SEED}

\subsection{Construction of the Library for BIM Modelling}

The BIM model is a 3D modelling technique and a design tool with object information. Therefore, the construction of a library that includes object information is required. To assess G-SEED evaluation items; this is the purpose of this study, a library of wall, floor, window, and door, which are the main elements comprising buildings, along with corresponding environmental performance data and other basic data, was made as shown in Fig.1.

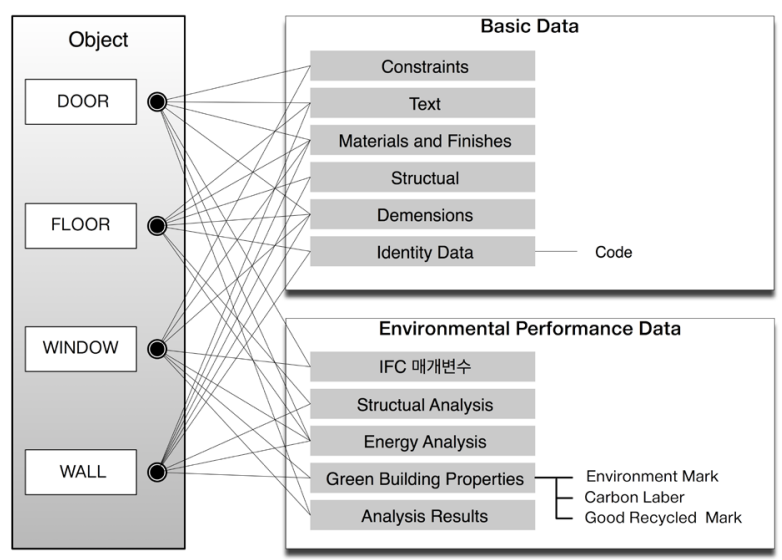

Fig.1. Data Structure of Library

\subsection{Extraction of BIM Model Data}

BIM modelling is implemented using the library that includes environmental performance information, and the applicability of G-SEED evaluation items is analysed via the extraction of BIM model data. For the extraction of BIM data, the schedules(txt) method, a method to extract Autodesk Revit ${ }^{\circledR}$ data, and the open file format Green Building XML (gbXML) were used. The schedules is the table mode where the data extracted from the element characteristics of the building modelled with Autodesk Revit ${ }^{\circledR}$ is marked. The data that changes when modifying a model is automatically updated in the schedules, such that data can be extracted reflecting the change. The schedules method is compatible with other software such that schedules can be sent to different software, such as spreadsheets.

gbXML is a tool for building design models and for engineering analysis. gbXML is an open file format developed to easily transport building information using a consistent format and to support interoperability through processes. Therefore, this method has a merit in that it can be interlocked with BIM software and implemented in a fast and simple manner because of its XML structure. Moreover, editing and inputting additional information is simple because the interface is intuitive.

From the information listed in Table 2., the difference of the attribute information extracted from the schedules and gbXML can be found. The schedules can extract information such as basic area and volume
Table 2. Extraction Method of BIM Data

\begin{tabular}{lll}
\hline \multicolumn{1}{c}{ Division } & \multicolumn{1}{c}{ Schedules(txt) } & $\begin{array}{c}\text { Green Building } \\
\text { XML (gbXML) }\end{array}$ \\
\hline Extraction & Area, Volume, Level, & Location, room \\
Data & H e i g h t, W i d t h, & area, volume, \\
& Structural, U-Value, & Building Storey, \\
& S p e c i f c H e a t, & Surface Name, \\
& Thermal Conductivity, & Opening \\
& Environmental Mark & \\
\hline
\end{tabular}

of building space; in particular, the schedules can send the environmental performance information included in the library. gbXML extracts information about the inner space of buildings as well as the building elements that comprise the space. Accordingly, to judge the applicability of G-SEED items to BIM, the data required to evaluate the items should be identified; then, these items should be evaluated by choosing a method that can provide suitable information.

\subsection{Method of Applying BIM to G-SEED}

Using BIM modelling, data attribute information and object information that suite the requirements by item subsection is identified; then, the extraction availability is analysed. The information extracted by this analysis is catalogued to build a database and utilized as input data by the algorithm of a formula of the process system constructed in advance in accordance with the purpose of this study. In addition to the automatic input method that directly uses the input data extracted through the BIM model for evaluation, a checklist method and a user input method were utilized. The checklist method and the user input method are used to assess the items that cannot be evaluated quantitatively or through BIM data.

\subsubsection{Automatic Input Method}

The automatic input method is used to evaluate data extracted through BIM modelling. Users perform BIM modelling utilizing the library that includes environmental performance information. The BIM model data is sent to the schedules of Autodesk Revit ${ }^{\circledR}$ and to the open file format gbXML to be substituted into the formula that was input and calculated in advance. Then, the score and certification class are decided according to standards.

The detailed modelling for all building components is not available when evaluating G-SEED detailed items. Accordingly, an LOD setting is required to assess G-SEED evaluation. The BIM modelling level is decided

Table 3. Contents of LOD Steps to Evaluate G-SEED Items

\begin{tabular}{|c|c|}
\hline LOD Steps & Contents \\
\hline LOD 100 & $\begin{array}{l}\text { Items to be evaluated as information through } \\
\text { surrounding site environment and mass shape. }\end{array}$ \\
\hline LOD 200 & $\begin{array}{l}\text { Items related to building element plan and } \\
\text { plane plan. }\end{array}$ \\
\hline LOD 300 & $\begin{array}{l}\text { Items to be evaluated as substantial modelling } \\
\text { of building elements. }\end{array}$ \\
\hline LOD 400 & $\begin{array}{l}\text { Items related to facility, pipe, etc. associated } \\
\text { after MEP modelling. }\end{array}$ \\
\hline LOD 500 & $\begin{array}{l}\text { Items related to maintenance and management } \\
\text { after construction, which are information } \\
\text { identical to real buildings. }\end{array}$ \\
\hline
\end{tabular}


by judging the LOD step of the items that can be judged through the automatic input method. Based on the LOD step definition (AIA, 2008) the content of BIM modelling by LOD steps used to evaluate G-SEED certification items is defined as listed in Table 3. (Kim et al., 2013).

Upon the analysis of the LOD steps of the automatic input method, G-SEED items can be evaluated through BIM modelling of the LOD 300 step.

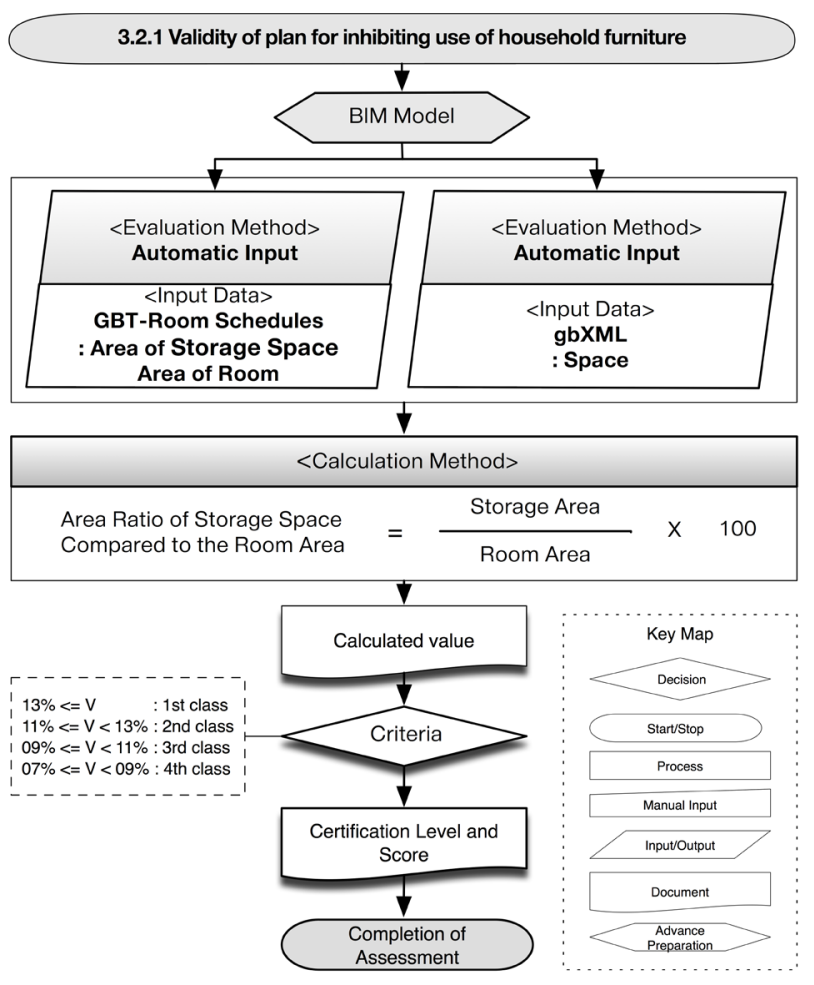

Fig.2. Automatic Input Method

\subsubsection{Checklist Method}

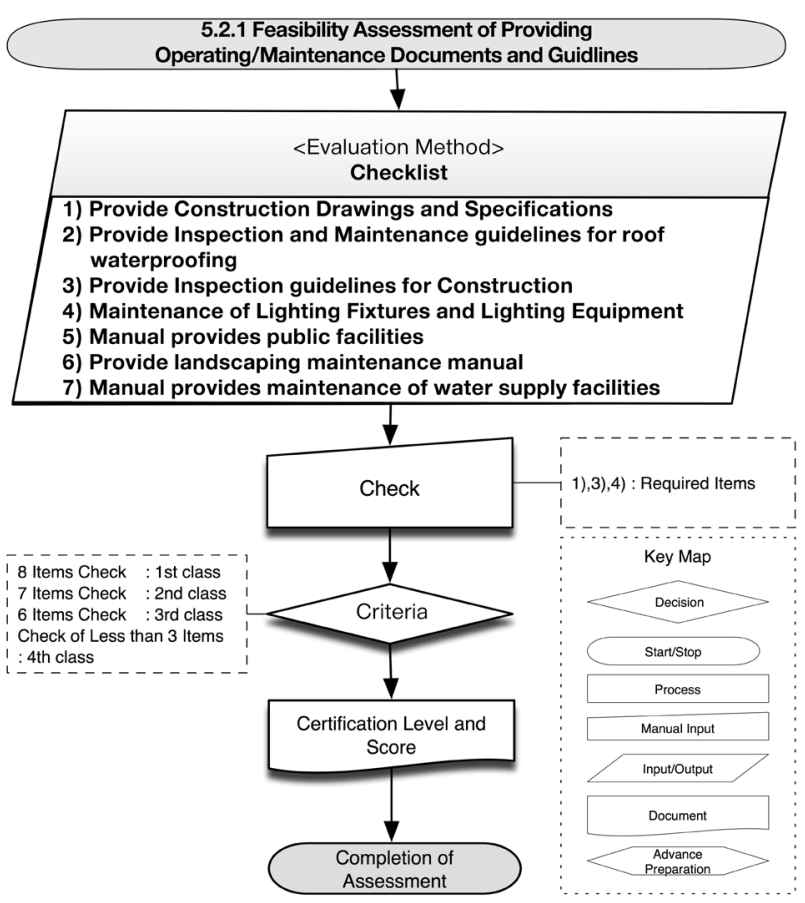

Fig.3. Checklist Method
Among certification items, with the checklist method, users can see the standards and directly verify the corresponding value to obtain a result. This method is applied to quantitative items that cannot be evaluated using BIM data. For example, '5.2.1 Items related to management/maintenance of documents and validity of guidance provision' as shown in Fig.2. is used to evaluate whether manuals and guides for effective management and maintenance are provided to building managers; thus, this item cannot be judged through the data extracted by the BIM model. Therefore, users can determine whether the documents have been provided and directly check the corresponding items. Consequently, the item score is decided based on the number of checked items, and certification classes can be granted.

\subsubsection{User Input Method}

This is the method through which users directly input values into a pre-set evaluation formula to obtain results. With respect to the information required to evaluate items, if the data cannot be extracted using the BIM model, users can directly input data values.

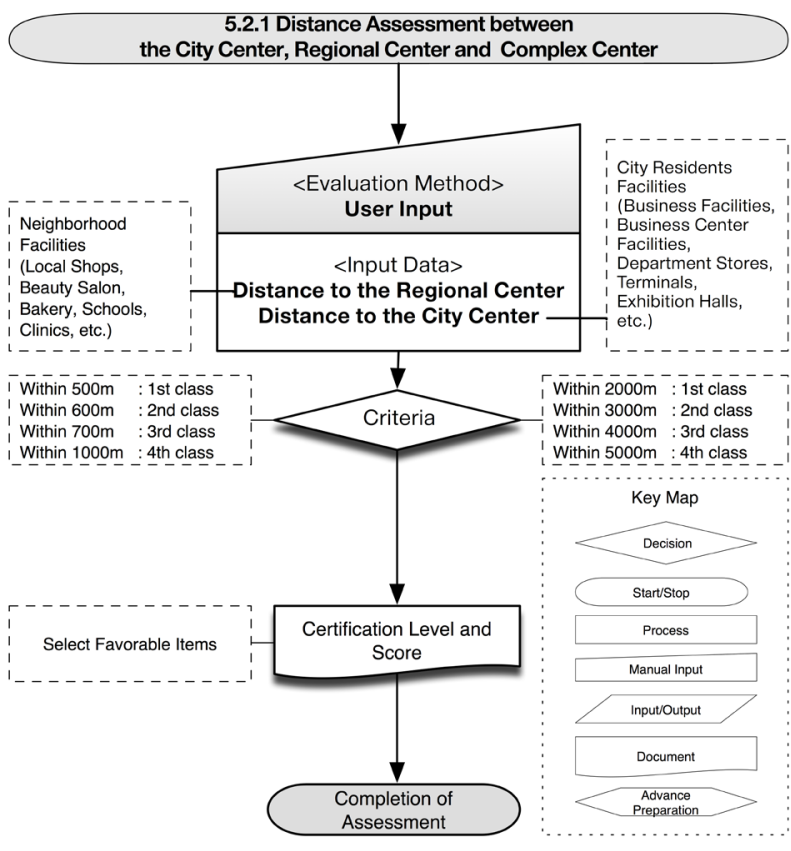

Fig.4. User Input Method

For example, in Fig.3., with respect to '1.4.3 Items related to the distance between city centre/regional centre and complex centre', the straight-line distance between city centre/regional centre and complex centre is measured, then the certification class and score are granted according to the standards. The distance to the regional centre and the city centre cannot be known through the BIM model; therefore, users can directly input the distance and conduct an evaluation.

By classifying the application of the BIM method to G-SEED, a total of five items could be evaluated using 11 automatic input items, 15 checklist method items, ten user input method items, and five automatic input and user input items. 
Table 4. Method of Applying BIM to G-SEED

\begin{tabular}{cccc}
\hline Application & Items & Percent & $\begin{array}{c}\text { Total } \\
\text { (Items) }\end{array}$ \\
\hline Automatic Input & 11 & $26.8 \%$ & \\
Checklist & 15 & $36.6 \%$ & 41 \\
User Input & 10 & $24.4 \%$ & 41 \\
Automatic Input \& & 5 & $12.2 \%$ & \\
User Input & & \\
\hline
\end{tabular}

\section{The Application of GBT to G-SEED \\ 4.1 GBT Concept}

GBT is a BIM-based template used to construct the evaluation environment to assess G-SEED certification. GBT includes the guide platform GBT (i) for the modelling with which environmental analysis (energy performance, $\mathrm{CO}_{2}$ production) is available. GBT also includes GBT (0) that links to G-SEED, and whose purpose is to support G-SEED. Accordingly, GBT is defined as the template to obtain appropriate outcomes by automatically constructing the environment that links to the certification program using BIM.

\subsection{GBT Structure}

To obtain the G-SEED outcome, which is a role of GBT, GBT can be set by dividing it into GBT (i) with a structure capable of modelling and analysing the system, and by GBT (0) with the structure by which the environment that links to the system is made, as shown in Fig.5.

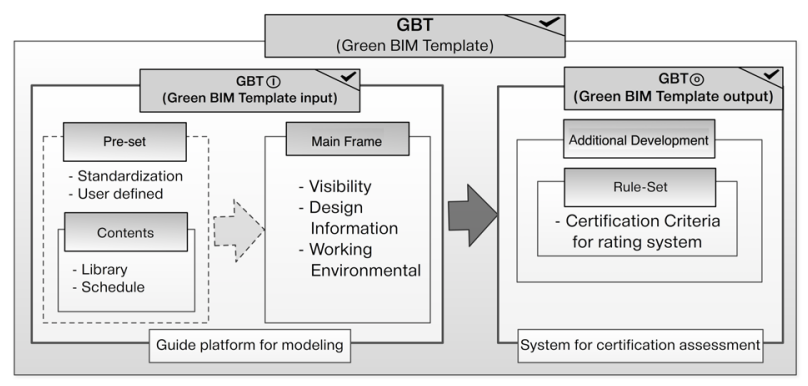

Fig.5. GBT Structure

GBT (i), the platform guide for modelling, is set by dividing it into Pre-set and Mainframe Using Preset, users can verify and modify the required working types with a View template. Pre-set is where the predetermined values of the library that is added with standardization, user definition, and environmental performance information, along with the information of arrangement elements, are set in advance. Mainframe is the platform where modelling work is performed through the library that is predetermined in Pre-set. The data for G-SEED evaluation is verified with preset data; then, BIM modelling is implemented.

The data extracted from the BIM model is the predetermined value of the rule-set of GBT (0), which is our newly developed system environment. This is the element by which an algorithm is set by a method for obtaining the result of G-SEED and where the result can be confirmed. The final G-SEED certification result passes through the GBT (i) and GBT (0) processes.

\subsection{GBT Application Scenario}

GBT is a template that provides a modelling guide to evaluate BIM-based G-SEED and can be interoperable with BIM-based certification programs. GBT is involved in the construction of the process by which the results of the G-SEED evaluation by a BIM-based template can be obtained. Accordingly, constructing a scenario for the utilization of BIM is required to evaluate G-SEED items.

As seen in Fig.6. GBT consists of five steps: the DATA step, the BIM modelling step, the information extraction step, the analysis step, and the result step. In this process, GBT (i) suggests a BIM modelling guide and provides a data input environment. GBT (0) provides a data output environment and obtains the final G-SEED result via interlocking with an evaluation system.

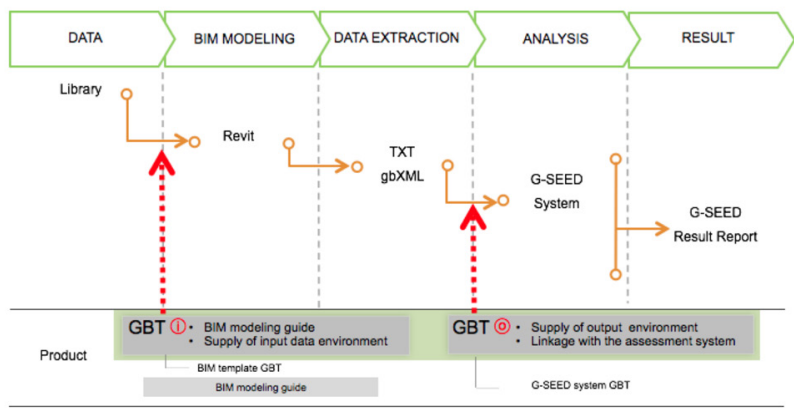

Fig.6. GBT Application Scenario

In the GBT application scenario, the BIM writing tool Autodesk Revit ${ }^{\circledR}$, which is GBT (i), is used for the BIM-based G-SEED evaluation process with respect to tool utilization, as shown in Fig.7. In addition, the BIM data link platform Microsoft Access, which is GBT (0), and the evaluation reporting system Microsoft Excel are used.

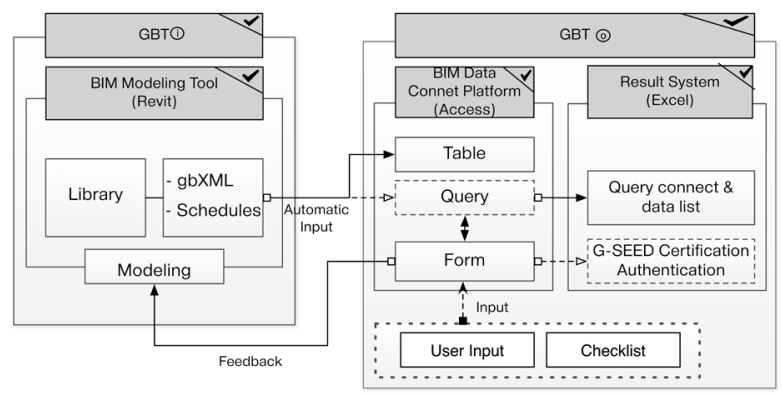

Fig.7. Process for BIM-based G-SEED Assessment

In GBT (i), the constructed library of the BIM writing tool is used for BIM modelling. Data is sent through a BIM model, and the data sent are imported to a BIM data link evaluation platform, which is GBT (0) process, such that the database can be constructed. A query is set to coordinate and process the imported data.

Form is the environment where users can easily identify the data set by a query by visualizing it. The 
user input method and the checklist method work with the query; therefore, the score and class of all items can be verified. If an unsatisfactory result is obtained, the users can verify the score of each item; therefore, the users can easily revise the BIM model and make any appropriate modifications.

The result reporting system is directly linked to the query, which is the BIM data link evaluation platform; thus, the score and class of each item can be verified through data sharing and the final result can be verified through the final G-SEED result report.

\subsection{GBT (i) Application}

GBT (i) is a template that constructs the BIM model by providing the BIM modelling guide to evaluate G-SEED and extract related information.

\subsubsection{BIM Modelling}

Modelling is performed using the library that includes environmental performance information. As explained for the GBT (i) structure, in the Pre-set, the library of door, floor, window, and wall, which are building design elements, is constructed as listed and included in a template such that users can choose the elements necessary to conduct modelling.

The BIM model that uses the library is a one-story apartment building (duplex) with two units that are $500 \mathrm{~m}^{2}$ in size. To make the surrounding environment available for G-SEED evaluation, the entire site, a nature strip, adjacent buildings, a community centre, a public facility for residents, bicycle storage, and a food waste treatment facility were subject to modelling.

\subsubsection{BIM Data Extraction}

If a BIM model is made, the information should be extracted for G-SEED evaluation. Table 6 . demonstrates the schedules template that was set in advance at GBT (i), and the appearance of the schedules and gbXML, which are the methods used to extract information.

\begin{tabular}{|c|c|c|c|}
\hline Division & GBT & Schedules(txt) & gbXML \\
\hline Image & 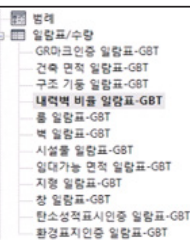 & 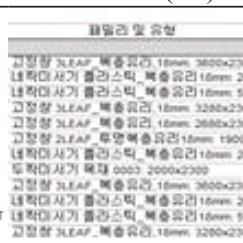 & 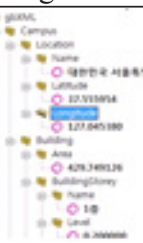 \\
\hline Part & \multicolumn{3}{|c|}{$\begin{array}{l}\text { BIM Modelling Guide, } \\
\text { Environment of Input Data }\end{array}$} \\
\hline
\end{tabular}

For BIM data extraction, gbXML, another method to extract data, can evaluate three items, which is a smaller number compared to the schedules method. However, gbXML is linked to the basic building information (user information, building location, evaluation date, etc.) and other BIM software; thus, gbXML can verify the form and conduct necessary simulation.

\subsection{GBT ( Application}

GBT (O) consists of a BIM data link evaluation platform that imports the extracted information into the BIM model and processes the information to evaluate G-SEED, then verifies the class and score of each item, and reports the result that verifies the final score and certification class.

\subsubsection{Application of BIM Data Link Evaluation Platform}

The extracted data is imported into the BIM data link platform, which consists of a table, query, and form as demonstrated in Table 8 . The table is the database that imports gbXML, and the schedules are the data extracted from the BIM model. G-SEED's detailed evaluation items, with respect to '3.4.1 Verifying the use of green certification product to recycle available resources', the products with the GR mark certification and the products without the certification are all extracted from the items used to evaluate the number of products that received the GR mark. However, only the products that received the GR mark certification are required; therefore, only the certified product data are extracted, and the products that did not receive certification through the query are excluded. Accordingly, the query sets the data imported into the table in accordance with the necessary use, such as combination and process. The form provides the environment such that users can verify score and class by visualizing the data that was set in the query. In addition, users evaluate the user input method and checklist method using the form.

The score and certification class by item can be verified in the form; consequently, this form provides feedback to users. Before interlocking to the result reporting system, users can verify the G-SEED certification class through the form. In addition, the form suggests the standard for a higher class such that users can determine how to improve certain parts.

\subsubsection{Application of Result Reporting System}

GBT (O) includes the work performed in the BIM data link platform, and is the system for interlocking with the result reporting system. The result reporting system largely consists of three sections. As Table 7. demonstrates, this system is divided into the section where the data list linked to the query is organized, the section where the score of each item is computed using the data, and the section where the certification class of G-SEED evaluation items and G-SEED building certification class are obtained.

The interlocked query is updated automatically with the addition and update of new data in the table. The updated query data can be imported using the interlocking function by importing the query data from Excel similar to the connecting part of the query data. This data is interlocked to an Excel spreadsheet where formulas are input in advance to compute the score by item, such that the score and class of each item are computed automatically. Lastly, all information for G-SEED certification are interlocked with the spreadsheet constructed in advance, such that the 
score and graph of each area, and the final score and certification class obtained by adding the scores of all areas, are verified.

\section{Plan for Use \\ 5.1 BIM-Based Certification Procedure}

We propose the BIM-based certification procedure shown in Fig.8., which can improve the problems in the existing certification procedure. The BIM model can produce a $2 \mathrm{D}$ blueprint and related information, thereby replacing self-evaluation papers and the evaluation documents submitted for the existing certification with the BIM model and saving waste of resources and time. Users perform BIM modelling using GBT, a BIM-based certification system, before the main certification, and then compute the G-SEED certification score in advance using BIM data. Subsequently, the verification and supplementing of items that obtain low scores can be performed; thus, users can obtain the required certification class. In the main certification, a judge assesses a site based on the evaluation document and the data extracted from the BIM model, and provides a final G-SEED certification class quickly and accurately using GBT to evaluate the final green certification class.

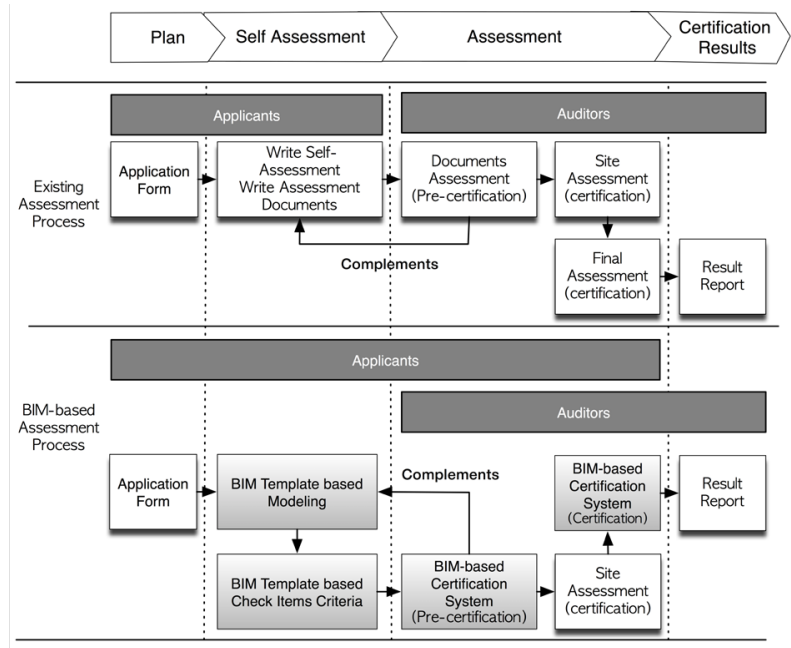

Fig.8. BIM-Based Certification Procedure

\subsection{The Level of BIM Modelling for G-SEED Certification}

We were able to define the level of BIM modelling for the certification evaluation by classifying it into four categories via the method by which the BIM data of G-SEED evaluation items is formed. The correlation between LOD level of G-SEED items and the four steps of the categories are listed in Table 6.

For a site plan, modelling with the LOD 100 level is required, the LOD 200-300 level is required for building plans, the LOD 300 level is required for interior and exterior decoration, and the LOD 400 level is required for the system plan. As mentioned in previous paragraphs, using the LOD definitions of the BIM model for G-SEED certification means that
Table 6. Correlation Between LOD Steps and Building Design Elements

\begin{tabular}{|c|c|c|}
\hline LOD Steps & $\longrightarrow$ & Building Design Elements. \\
\hline LOD 100 & $\longrightarrow$ & Site plan \\
\hline LOD 200 & $\rightarrow$ & Building plan \\
\hline LOD 300 & $\rightarrow$ & Interior and exterior \\
\hline LOD 400 & $\longrightarrow$ & System plan \\
\hline LOD 500 & & \\
\hline
\end{tabular}

certification items can be evaluated by LOD steps, even when the items are the LOD 500 step, which is perfect modelling. In other words, users can assess the G-SEED evaluation items that correspond to each LOD step while conducting the LOD 100-500 step for BIM modelling. By improving the process for BIM-based G-SEED evaluation as shown in Fig.9., users additionally develop an information input window through BIM modelling work, by which the information of the user input method and the checklist method are also provided, thus enabling the evaluation of G-SEED items.

For example, to evaluate '6.1.2 Green ratio of natural soil', the entire site area and the green area of natural soil are required such that an evaluation with the modelling of the LOD 100 step can be performed. Similarly, after completing BIM Modelling of the LOD 100 step, the information of the G-SEED items that can be evaluated through the automatic input method is sent to the BIM data link evaluation platform. The template in which the information from the user input method and checklist method can be entered is also made. The template is constructed by classifying data into site plan, building plan, system plan, and interior and exterior decoration plan, and the information is entered after completing the BIM model. Because the LOD 100 step corresponds to the site plan, users can directly evaluate G-SEED items that can be identified with the information of the LOD 100 step at the constructed template window with the user input method and the checklist method.

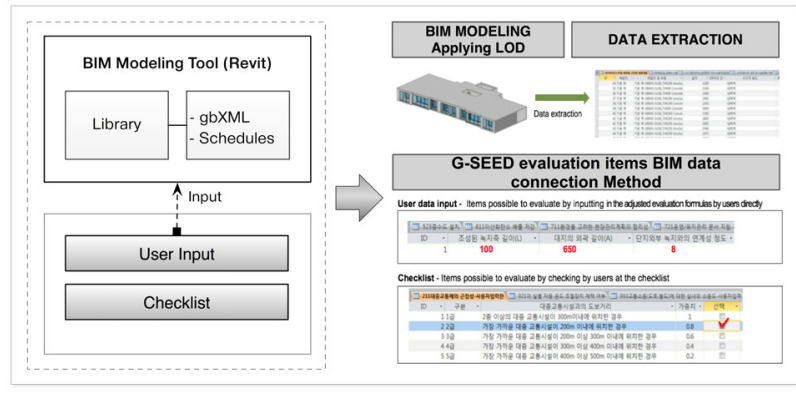

Fig.9. G-SEED Evaluation Method by BIM Modelling Step

Using the G-SEED evaluation method by the BIM modelling step, users can verify the G-SEED certification score while designing. To acquire the targeted certification class through this, a quick design change and the modifications of the BIM model are available. 


\section{Conclusion}

For green buildings, integrated analysis should be considered from the design stage based on information such as objective analysis results of environmental data, energy simulation, and input variables. This can be accomplished through BIM, a 3D design tool that imports the information related to buildings into a database and links it.

This study proposed GBT, a BIM-based evaluation environment system, in order to support G-SEED, a certification program that can judge green building performance, to be evaluated based on BIM.

GBT was classified based on G-SEED evaluation items into GBT (i) that is involved in providing a library added with environmental analysis data and guiding, and GBT (0), a G-SEED evaluation system. Subsequently, specific information was extracted after BIM modelling through GBT (i), BIM data was imported into a database through GBT (0), and lastly, the final certification class could be confirmed by evaluating G-SEED items.

The G-SEED item evaluation method was constructed with 11 automatic input methods, ten user input methods, 15 checklist methods, and five automatic input and user input methods; thus, a total of 41 items were systemized. In this process, GBT provided a screen through which users can confirm the results by G-SEED sub-item, such that if the result does not meet the class and score standard users require, the users can make quick decisions by confirming the corresponding data through the evaluation item.

The utilization of GBT provides building designers with eco-friendly libraries and templates, such that they can readily construct BIM models and establish a substantial strategy for eco-friendly designs during the design process. In addition, using GBT, operators can evaluate through simplified judgment procedures and with objective information, thus providing reliable judgment results to users and contributing to the utilization of G-SEED. Managers can construct systematic databases and distribute the information to users, which will be the basis for the utilization of green buildings.

Hereafter, we plan to develop a web environment without making the BIM data link platform dependent on a specific program, in order to improve users' accessibility and convenience.

\section{Acknowledgement}

This research was supported by a grant (13AUDP-C067817-01) from the Architecture \& Urban Development Research Program funded by the Ministry of Land, Infrastructure and Transport of the Korean government.

\section{References}

1) Ahn, Y.-H., Pearce, A. R. and Hanmee Global Co. Ltd. (2012) Sustainable buildings and infrastructure: Paths to future, Maeil Business Newspaper.

2) AIA (2008) AIA Document, E202-2008.

3) Bae, G-J. (2011) A study on the criterion establishment of LOD (level of detail) for BIM model, Master's Thesis, Hanyang University.

4) Choo, S-Y, Lee, G.-H. and Park, S-G. (2012) Study on setting the modeling level for green BIM guideline development, Journal of Architectural Institute of Korea, 28 (6).

5) Committee on Green Growth, the result of greenhouse gas emission by local government and emission characteristics. (2011) Research Report.

6) Gang, H.-J., Mun, S-Y., Lee, S-H. and Jun, H.-J. (2013) A Survey on Priority of Elements of Development of BIM Template for Small and Middle Architectural Design Firms, Journal of Architectural Institute of Korea, 29 (3).

7) Jang, W.-J., Kim, M.-K., Kim, S.-W. and Jun, H.-J. (2009) A Basic Study on a BIM-based Design Process for Sustainable Architecture, Journal of Korean Culture and Space Architectural institute of Korea, 26.

8) Kim, I.-S., Kim, M-K. and Jun, H.-J. (2013) A Study on the Assessment Method of BIM-based Architectural Design for Approaching Sustainable Architecture: Focused on G-SEED in Korea, Journal of Society of Design Convergence, 12 (5).

9) Kim, M-K., Noh, M-S., Kim, I-S. and Jun, H-J. (2012) A Study on the Applicability of GBT (Green BIM Template) for BIM-based Green Building Certification System: Focused on CASBEE in Japan, Journal of Society of Design Convergence, 11 (4).

10) Kim, S-Y. and Kim, H.-B. (2010) Study on the plan for improving Korea's green building certification program, through the research of BREEAM and LEED, Journal of Architectural Institute of Korea, 26 (12).

11) Krygiel, E. and Nies, B. (2010) Green BIM: Successful sustainable design via BIM, Spacetime, translated by Kim, M.-S. and Jeong, I.-Y.

12) Kwok, A. G. and Grondzik W. T. (2011) Green studio: Environmental strategy for basic design, Spacetime, translated by Song, G.-D., Kim, M.-S. and Jeong, I.-Y.

13) Lee, B-C. (2010) Study on the BIM introduction plan of Korean design offices, Master's Thesis, Soongsil University.

14) Lee, B-Y., Lee, B-H. (2012) Study on the integrated design guideline system based on green building certification program, Journal of Architectural Institute of Korea, 28 (6).

15) Lee, S-H., Kim, M-K., Choi, H-A. and Jun, H-J. (2011) A Study on Analysis of the Template Component for the Development of BIM Template, Journal of Ecological Environment and Architectural institute of Korea, 11 (2).

16) Noh, M-S., Kim, I-S., Kim, M-K and Jun, H-J. (2013) A Study on Developing Evaluation Environment of Green Building Certification Criteria Using GBT (Green BIM Template), Journal of Architectural Institute of Korea, 29 (6).

17) Ofori, G. (1998) Sustainable construction: principles and a framework for attainment, Construction Management and Economics, 16 (3).

18) Reed, B. (2009) The integrative design guide to green building: redefining the practice of sustainability, John Wiley \& Sons.

19) US Green Building Council (USGBC) (2009) LEED Reference Guide for Green Building Design and Construction, Available from the Green Building Certification Institute.

20) Yang, H.-M. (2012) A study on the development of template for BIM-based architectural design, Master's Thesis, Hanyang University. 